\title{
The Development of the Tester for the DSD Series High Frequency Electric Brush Planting Power Supply
}

\author{
Rui Zhang \\ Department of Computer Technology \\ Yanbian University \\ Yanji 133002, China
}

Hu Jin

Shenyang University of Technology

Shenyang 110023, China

\author{
Xiangfan Piao* \\ Key Laboratory of Nature Resource of the Changbai \\ Mountain and Functional Molecular \\ Yanbian University \\ Yanji 133002, China \\ e-mail: pxf@ybu.edu.cn
}

\begin{abstract}
In order to shorten the detection time of DSD series high frequency electric brush plating power supply, we designed a tester for the power supply, which can facilitate data analysis and maintenance of power supply for the staff. Working principle, the hardware structure and software flow are depicted here. The control system to STC12C5616AD microcontroller as the core, which can collect high pressure and low pressure data of power supply, the tester also targeted collect IGBT voltage related parameters. We can observe and switch the display interface through the LCD touch screen display, the tester not only provides a reliable guarantee of data for power failure rapid diagnosis, but also improves the efficiency of the brush plating power supply test effectively.
\end{abstract}

Keywords- brush plating power supply; the microcontroller; IGBT; data acquisition; detection means.

\section{INTRODUCTION}

Electric brush plating is known as brush plating, it belongs to a local fast plating that outside the groove. In recent years, electric brush plating as a new way of electroplating is on the rise, it is a mechanical maintenance for the main purpose of surface engineering technology [1].The electric brush plating has characteristics of the equipment of portable, simple operation, flexible process, fast plating rate, low power consumption, high quality of coating and little pollution to the environment, therefore it is widely used in mechanical parts without disassembling the repair and field repair [2,3]. DSD series high frequency electric brush plating power supply is free to choose pulse waveform brush plating or DC waveform brush plating. When we select pulse waveform brush plating, we can adjust the parameters such as frequency, duty cycle, voltage [4]. The coating of pulse waveform brush plating is more compact, lighter, and more resistant to corrosion, more resistant to discoloration than the coating of DC waveform brush plating, pulse waveform brush plating also can save the plating solution. Because of frequently being used in the construction site, detection of maintenance is limited by factors such as personnel quality, environmental conditions, it takes a long time to repair [5]. Now the maintenance methods not only increase the cost of production of enterprises, but also hinder the development of enterprises.

Based on the above issues, we developed the DSD series high frequency electric brush plating power supply tester. The tester is mainly collecting the high pressure parameters such as ripple amplitude of DC $300 \mathrm{~V}$, input voltage, input current and the Grid-Emitter threshold voltage of IGBT, it also can collect the low pressure parameters such as the voltage about $+5.1 \mathrm{~V}$, output voltage, output current and the voltage of overload protection. According to the related data of power device, the staff can shorten the detection time, and the tester also has a great advantage in terms of using easily.

\section{WORKING PRINCIPLE OF THE SYSTEM}

\section{A. Constitution of the Tester}

Control system of the tester is mainly composed of the microcontroller, peripheral circuit, drive circuit, switch power supply and TFT-LCD. The microcontroller collect different data from the high pressure circuit and low pressure circuit by connecting different interface. After that, the data will be display on the LCD screen. Site operators can through these data to determine the power supply working condition. Fig .1 illustrates the electrical schematic diagram of the total system. 


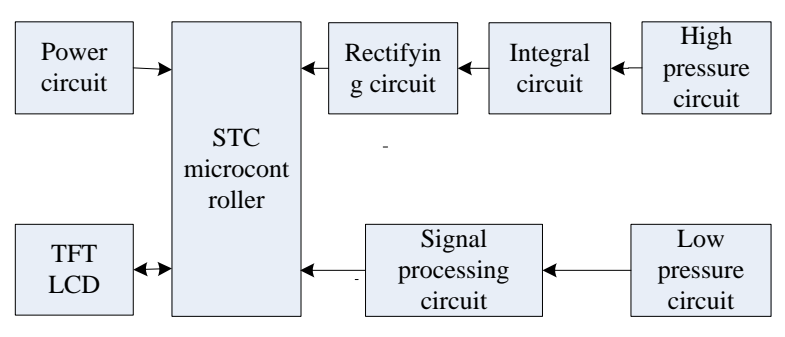

Figure 1. Block diagram of system hardware.

According to the characteristics of the test parameters, test parameters can be divided into the part of high pressure and the part of low pressure. The tester is mainly using hall sensor [6], precision rectifier circuit [7] and integral circuit in the aspect of hardware, so the voltage and current data can be collected. The interrupt and capture mode play a major role on software for data processing. The interactive human-machine communication interface (HCI) [8] is composed of MCU and LCD display, the MCU and LCD display can communicate with each other through MAX232. Man-machine interface is composed of two different interfaces, the interface of high pressure includes input voltage, input current and IGBT related parameters, the interface of low pressure part includes output voltage changing frequency and threshold detection.

\section{B. $\quad$ Main Test Parameters}

The microcomputer can determine the high or the low pressure part by detecting port P2.2.

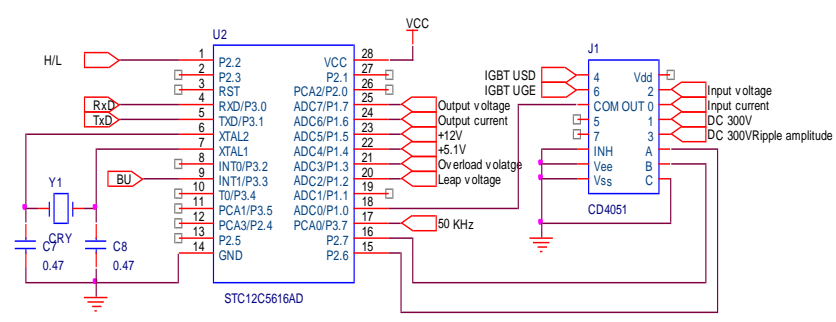

Figure 2. The system of pressure parameter interface diagram.

The low pressure part of the main measurement parameters including the voltage about $+5.1 \mathrm{~V}$, output voltage, output current, the voltage of overload protection and the frequency about $50 \mathrm{KHz}$. The DC output voltage is mainly collected as an average, and the collection of output current is through ring opening type hall sensor, the microcontroller calculate output power and display it on the LCD. The detection of voltage about $+5.1 \mathrm{~V}$ is through port P1.6, the microcontroller can test and determine whether the data is normal. If the data is abnormal, the buzzer will warn. The detection of frequency about 50 $\mathrm{KHz}$ use PCA hardware capture mode, the microcomputer connected with the signal through port P3.7. Low voltage system parameter interface is shown in Fig .2.

High pressure part interface is connected with the microcontroller by simulating electronic switch CD 4051. The microcontroller choose access channel by port P 2.7 and P2.6, public output is connected to the microcontroller through port P1.1. Main measurement parameters include the input current, input voltage, the voltage about DC 300 $\mathrm{V}$, the ripple amplitude detection of DC $300 \mathrm{~V}$ and the Grid-Emitter voltage threshold detection of IGBT [9]. The average input voltage is mainly collected by precision rectifier circuit and integral circuit. The collection of output current is also through ring opening type hall sensor, so the microcontroller can calculate the input power.

\section{SYSTEM SOFTWARE DESIGN}

\section{A. The Voltage Modulation Circuit Design}

Measurement for voltage data can effectively help site maintenance staff to analyze the working state of the power supply, but at the time of actual measurement, the measured amplitude of voltage could not match the test amplitude of microcomputer completely. At this point, we need to adjust the measured amplitude of voltage through voltage modulation circuit, so that it can finish part voltage parameters extraction. Part of the voltage modulation circuit shown in Fig .3.

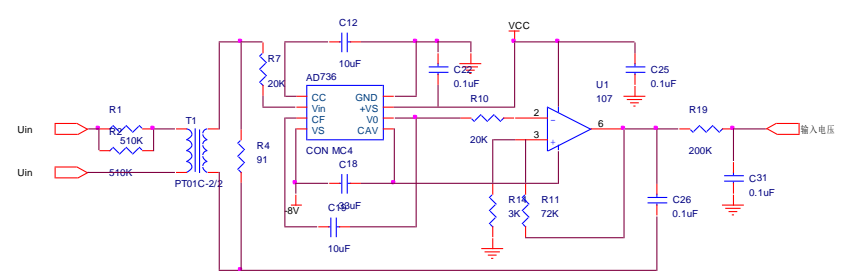

Figure 3. The The principle diagram of voltage modulation circuit

In the design of circuit, potential device adopts the current voltage transformer PT01C - 2/2, the transformer could turn the voltage signal into the current signal, Current limiting resistor is placed in the input circuit, we could adjust the value of the resistor and let the input current to $2 \mathrm{~mA}$ [10], so that the current and voltage meet the working conditions of the transformer.

At the time of voltage measurement, in order to accurate measurement of AC RMS voltage, we usually use AD736 as a true RMS-to-DC converter, the effective value of AC signal is converted into DC signal. The DC output voltage signal of AD736 transformation is weak, we need the amplifier to produce amplification of the signal, so that signal is input to the MCU.

\section{B. The Grid-Emitter Threshold Voltage of IGBT Test method}

The test parameters of IGBT Gate-Emitter threshold voltage $\left(\mathrm{U}_{\mathrm{GE}}\right)$ accord with national standard GB/T170071997 standard [11], but the tester uses some different test methods and makes some changes.

Grid-Emitter threshold voltage test: the Grid-Emitter threshold voltage of IGBT refers to the voltage which can make IGBT turn-on. When the Grid-Emitter voltage is lower than the threshold voltage, the IGBT is in the off state, When the Grid-Emitter voltage is higher than the threshold voltage, the IGBT is in the conduction state [12].

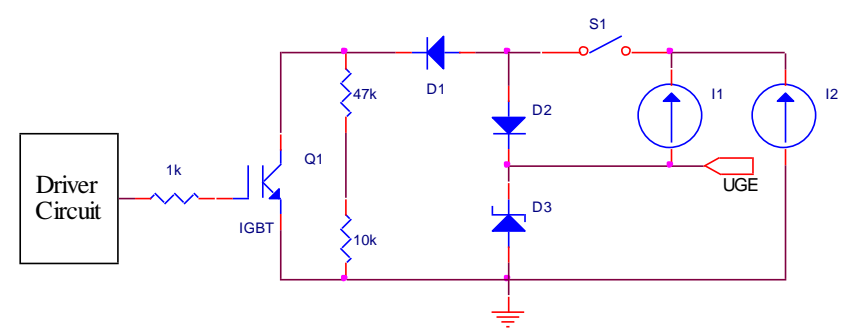

Figure 4. The principle diagram of Grid-Emitter threshold voltage test circuit. 
As shown in Fig .4, Q1 is the under test IGBT. The turn-off voltage measuring branch of IGBT is consists of resistor R1 and R2, The turn-on voltage measuring branch of IGBT consists of diode D1 and D2, switch S1, two current sources I1 and I2, and the resistance R2. D1 and D2 is the same diode, switch S1 can control the IGBT gate driving signal. D3 can protect the output stage circuit as a kind of output voltage regulator tube.

\section{The Frequency Modulation Circuit Design}

The measured data of transformation frequency and duty ratio can help in determining the failures of the power components, because the measured frequency waveform is not standard waveforms, the microcomputer measured data may not be accurate, so we need to modify the waveform.

In this paper, we use the zero comparison method to measure frequency, circuit shown in Fig .5. The output voltage is equal to $-\mathrm{U}_{\text {om }}$ when the input voltage is higher than zero, and when the input voltage is lower than zero, the output voltage is equal to $-\mathrm{U}_{\text {om }}$, the circuit converts the original waveform to square waveform. After that, we have the microcomputer to with PCA capture mode, so that we can measure accurate frequency data. D1 and D2 have protective effects, they can confine the voltage signal to the range of the microcomputer.

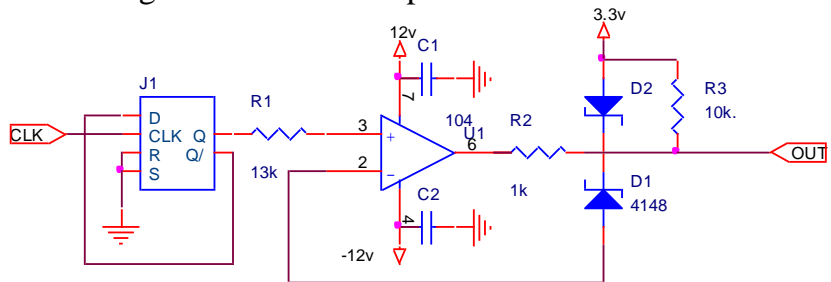

Figure 5. The principle diagram of frequency modulation circuit.

\section{System software design}

System software design is constituted by main program, the data of low pressure acquisition subroutine, the data of high pressure acquisition subroutine, display subroutine, interrupt subroutine and delay subroutine. Program main function modules are LCD screen initialization, data acquisition and signal processing and control module. LCD screen initialization including related parameters initialization, display interface initialization and switch interface initialization.

First of all, the LCD screen start to initialize. After the initialization, the microcontroller run the data of low pressure acquisition subroutine, the data such as output voltage are displayed on the LCD screen. At this time, the microcontroller waiting to run the data of high pressure acquisition subroutine. If the LCD keyboard is triggered, the microcomputer will run the interrupt program, the interface switch to the high pressure data acquisition circuit. The data of high pressure can be collected in this way. At last, the microcomputer will stop to waiting for the next trigger signal.

\section{THE EXPERIMENTAL RESULTS}

We test the system of the DSD-50M brush plating power supply which powered from $220 \mathrm{~V}, 50 \mathrm{~Hz}$ power supply, and we use an oscilloscope to observe the signal of $\mathrm{U}_{\mathrm{GE}}$, the driving waveform is shown in Fig .6.

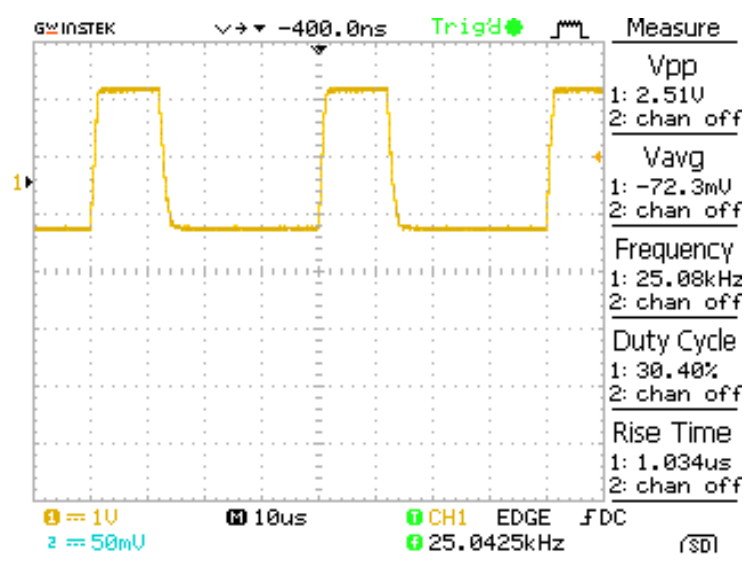

Figure 6. The driving waveform of IGBT

We use the digital multimeter GDM-451 to measure the voltage of $\mathrm{U}_{\mathrm{GE}}$, and the effective value is $2.515 \mathrm{~V}$. We can infer that the modulation circuit converts the voltage into $2.51 \mathrm{~V}$ from Fig .6, so that the circuit achieves the desired effect.

The brush plating power often work under full power, the duty ratio of driving voltage is very important to the employee who is responsible for maintenance. We get Fig 7 from the oscilloscope, the $\mathrm{CH} 1$ on behalf of IGBT driving waveform, $\mathrm{CH} 2$ on behalf of the corresponding control voltage.

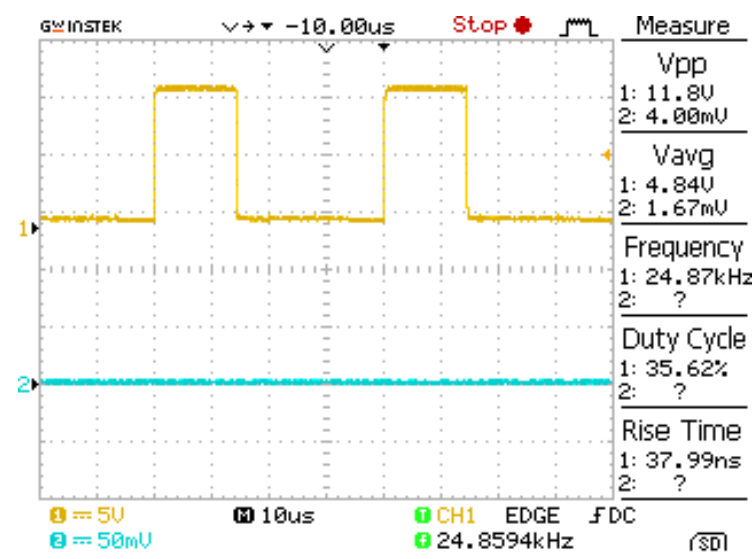

Figure 7. The trailing time waveform of IGBT

When the first drive pulse disappears the second drive pulse can't appear at once because of the tail current within IGBT, otherwise the second pulse will turn on the fullbridge IGBT and cause a short-circuit, even the IGBT can be damaged. The dead- time calculation formula as in

$$
\mathrm{T}=\left(40-2 * \mathrm{~T}_{\mathrm{H}}\right) / 2
$$

$\mathrm{T}_{\mathrm{H}}$ refers to the high level time of drive pulse. $\mathrm{T}$ refers to the dead - time.

In order to test the performance of our tester, we select a set of driving voltage. The idle duty ratio of different driving voltage is detected through the tester, we also use the oscilloscope to get the idle duty ratio, Duty ratio 1 refer to the test data by tester, Duty ratio 2 refer to the data by oscilloscope, dead - time calculated by the related data ,the corresponding data is shown in Tab.1. 
TABLE I. THE ANALYSIS FORM OF DUTY RATIO

\begin{tabular}{|l|l|l|l|l|}
\hline $\begin{array}{l}\text { Driving } \\
\text { Voltage }\end{array}$ & $\begin{array}{l}\text { Duty } \\
\text { Ratio 1 }\end{array}$ & $\begin{array}{l}\text { Dead } \\
\text { Time 1 }\end{array}$ & $\begin{array}{l}\text { Duty } \\
\text { Ratio 2 }\end{array}$ & $\begin{array}{l}\text { Dead } \\
\text { Time 2 }\end{array}$ \\
\hline $0.5 \mathrm{~V}$ & $1.73 \%$ & $19.31 \mathrm{us}$ & $1.75 \%$ & $19.30 \mathrm{us}$ \\
\hline $1.0 \mathrm{~V}$ & $10.35 \%$ & $15.86 \mathrm{us}$ & $10.28 \%$ & $15.89 \mathrm{us}$ \\
\hline $1.5 \mathrm{~V}$ & $18.55 \%$ & $12.58 \mathrm{us}$ & $18.65 \%$ & $12.54 \mathrm{us}$ \\
\hline $2.0 \mathrm{~V}$ & $27.46 \%$ & $9.02 \mathrm{us}$ & $27.39 \%$ & $9.04 \mathrm{us}$ \\
\hline $2.5 \mathrm{~V}$ & $36.18 \%$ & $5.53 \mathrm{us}$ & $36.03 \%$ & $5.59 \mathrm{us}$ \\
\hline
\end{tabular}

The on and off states of the IGBT is controlled by the control signal. Ideally, when the input signal cut off, IGBT turn off immediately. But the reality is entered IGBT turn on after a period of time. The turn - off time of IGBT is defined as the input signal to the collector current fall to open $10 \%$ of the current time. In fact, the time of $0.5 \mathrm{I}_{\mathrm{c}}$ to $0.1 \mathrm{I}_{\mathrm{c}}$ times 50 is equal to the turn - off time. The trailing time waveform is shown in Fig .8.

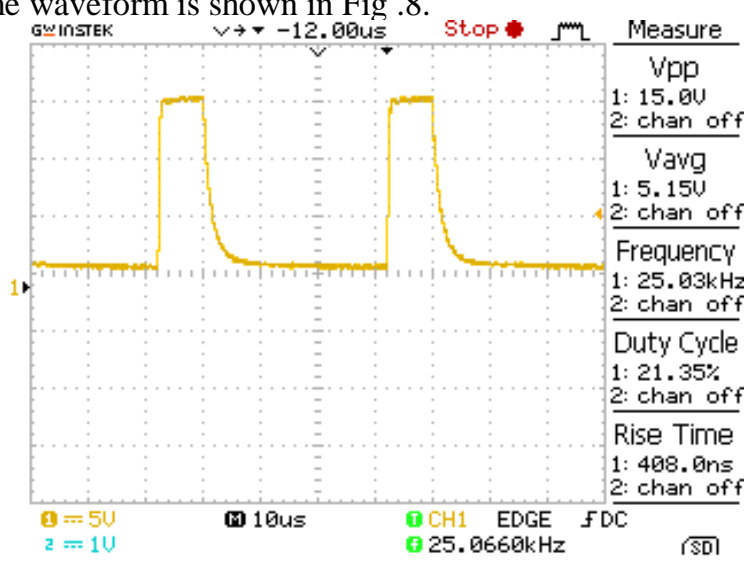

Figure 8. The trailing time waveform of IGBT

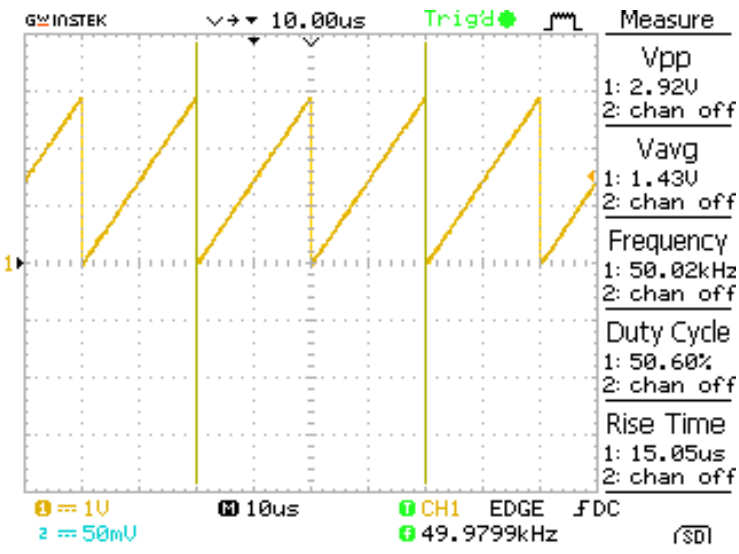

Figure 9. The frequency oscillation waveform

When we completed experiments about IGBT, the oscilloscope is be used to get the frequency oscillation waveform about $50 \mathrm{KHz}$ through the test circuit, the waveform is shown in Fig .9, the frequency can be adjusted to meet the requirements of the square waveform, the waveform is shown in Fig .10.

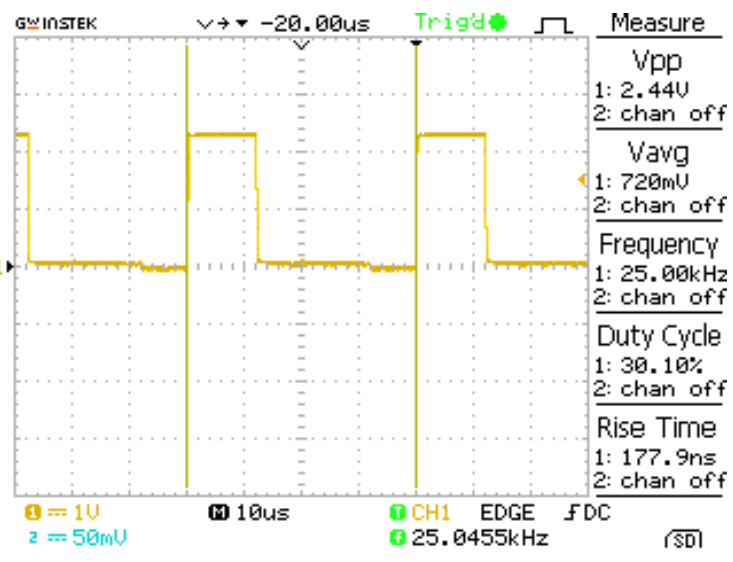

Figure 10. The waveform of transformation

The actual frequency is produced by the frequencygenerator, and we use the tester to get the measured frequency, the third line data refer to the relative error, the analysis form of frequency is Tab .2.

TABLE II. THE ANALYSIS FORM OF FREQUENCY

\begin{tabular}{|l|c|c|c|c|c|c|}
\hline $\begin{array}{l}\text { Actual } \\
\text { Frequency }\end{array}$ & 24500 & 24750 & 25000 & 25250 & 25500 & 25750 \\
\hline $\begin{array}{l}\text { Measured } \\
\text { Frequency }\end{array}$ & 24509 & 24756 & 24996 & 25255 & 25507 & 25743 \\
\hline $\begin{array}{l}\text { Relative } \\
\text { Error }\end{array}$ & $0.04 \%$ & $0.02 \%$ & $0.02 \%$ & $0.02 \%$ & $0.03 \%$ & $0.03 \%$ \\
\hline
\end{tabular}

Analysis of the measurement frequency data shows the relative errors of measured data are within $0.1 \%$, the precision satisfy the accuracy requirement of standard and site test.

\section{CONCLUSION}

The tester for the DSD series high frequency electric brush planting power supply can quickly collect high pressure and low pressure data of power supply. The working principle of the tester changes the traditionally artificial way of power detection means, good system operation is very simple. In this way, we can reduce the requirement for on-site staff and reduce the loss about which human improper operation brought, the efficiency of the brush plating power supply test is effectively improved.

\section{REFERENCES}

[1] Bell T, Mao K, and Sun Y. Modelling Surface Engineering Systems for Improved Tribological Performance. Surface and Coatings Technology, 2010, 15.pp. 108 109.

[2] Fengkuan Xie, Shujuan Zhuang, and Jianhua Du. The brush plating $\mathrm{Ni}$ plating in the seawater corrosion wear test. Journal of armored force engineering institute, 2011, 22.pp 79-82.

[3] Maozhong An. Plating theory and technology. Harbin institute of technology press, 2014.

[4] Hezhou Feng, Xu Feng. The design of CMOS switch type hall magnetic sensor. Instrument technology and apparatus. 2013,12.pp. $5-7$.

[5] Bosheng Xue,Xiaofang Ren. The man-machine interface system application in brush plating power supply. Plating and Finishing 2014,5.pp. 22-23.

[6] Nishad Patil, Diganta Das, Kai Goebel, et al. Identification of failure precursor parameters for Insulated Gate Bipolar Transistors (IGBTs) . International Conference on PHM. 2012,pp. 1-5. 
[7] U. Schwarzer, R. W. De Doneker. Power Losses of IGBTs in an inverter prototype for High Frequency Inductive Heating Applications. Industrial Electronics Soeiety. The 27th Annual Conference of the IEEE. 2009, 2.pp. 793-798.

[8] Lobsiger Y.kolar J W.Voltage of Current and temperature measurement concepts enabling intelligent gate drivers. European Center for Power Electronics Workshop-Electronics Around the Power Switch:Gate Drivers,Sensors and Control. 2011.

[9] Wang Y,Palmer P R,Bryant A T,et al.An analysis of high-power IGBT switching under cascade active voltage control. IEEE Transactions on Industry Applications. 2009,45pp. 861-859.
[10] H. Belmili, S. Cheikh, M. Haddadi, and C. Larbes. Design and development of a data acquisition system for photovoltaic modules characterization. Renewable Energy, 2010, 35pp. 1484-1492

[11] Kin Y S, Sul S k. On-line estimation of IGBT junction temperature using ON sate voltage drop. Industry Applications Conference, Thirty-Third IAS Annual Meeting. IEEE, 2010:853-870.

[12] Carsten B.A clipping pre-amplifier for accurate scope ,easurement of high voltage switching transistor and diode conduction voltages.Proceedings of the International Power Conversion, Intertec International, INC. 2012pp. 355-342. 